\title{
DESEMPENHO AGRONÔMICO DE VARIEDADES DE FEIJÃO-CAUPI NO PERÍODO DE ESTIAGEM EM CASTANHAL-PA
}

\author{
RENDIMIENTO AGRÍCOLA DE LAS VARIEDADES DE CAUPI BEAN EN EL \\ PERÍODO DE ENVASADO EN CASTANHAL-PA
}

\section{AGRICULTURAL PERFORMANCE OF CAUPI BEAN VARIETIES IN THE CASING PERIOD IN CASTANHAL-PA}

\author{
Lucas Fernando da Costa Lima ${ }^{1}$; Breno Barbosa dos Santos ${ }^{2}$; Gabriel Garreto dos Santos ${ }^{3 ;}$ \\ Domingos Sávio Morais Tavares ${ }^{4}$; Juliana Simões Nobre Gama ${ }^{5}$
}

DOI: https://doi.org/10.31692/978-65-991061-4-9.33-46

\begin{abstract}
RESUMO
O estudo da época de plantio do feijão-caupi tem grande importância para a sua produção, visto que, ele é bastante sensível à precipitação, temperatura, chuvas irregulares e mal distribuídas, juntamente com o período de estiagem, causam danos enormes às lavouras. Desse modo, este trabalho teve como objetivo avaliar o desempenho de variedades de feijão-caupi (Vigna unguiculata L.) no período de estação seca, assim como, fazer um resgate das sementes crioulas produzidas no nordeste paraense. $\mathrm{O}$ experimento foi realizado em campo localizado no Instituto Federal de Educação, Ciência e Tecnologia do Pará, campus Castanhal, conduzido de setembro a novembro de 2018. Foram utilizadas 4 variedades de feijão-caupi, sendo elas: BRS Novaera (conhecido como caupi branco), caupi vermelho (conhecido como mata fome) e caupi verde (conhecido como sempre verde), sendo todas encontradas em cidades pertencentes à região nordeste paraense, como Marapanim, Santa Maria do Pará, Irituia e Castanhal. O experimento foi conduzido em blocos casualizados com área de 9x5 m cada bloco, divididos em 4 parcelas de 4x2 m, respeitando o espaçamento de 1 metro entre parcelas dentro do bloco. As plantas foram observadas durante um período de 60 dias a partir da semeadura, sendo as variáveis de crescimento analisadas, diâmetro do caule, altura das plantas e massa seca da parte aérea, avaliados a cada 12 dias. Após a colheita foram avaliadas as variáveis de rendimento: número de vagens por planta, comprimento das vagens, número de sementes por vagem e peso de 100 sementes. Os dados obtidos foram submetidos a análise de variância e as médias comparadas pelo teste Tukey a 5\% de probabilidade. Para os períodos de avaliação, foi realizada uma análise de regressão polinomial. As variedades de feijão-caupi BRS Novaera, seguida da "sempre verde" e "mata fome" apresentam desempenho satisfatório no período de estiagem, sendo uma opção para o agricultor poder cultivar mais uma safra de feijão durante o ano. A variedade "mata fome" pode ser uma alternativa para adubação verde e recuperação de solos degradados, devido a produção expressiva de matéria seca e cobertura verde no solo.
\end{abstract}

Palavras-Chave: Vigna unguiculata L., semente crioula, rendimento

\section{RESUMEN}

El estudio del tiempo de siembra del caupí es de gran importancia para su producción, ya que es muy sensible a las precipitaciones, la temperatura, las precipitaciones irregulares y mal distribuidas, junto con la estación seca, causando enormes daños a los cultivos. Por lo tanto, este trabajo tuvo como objetivo evaluar el rendimiento de las variedades de caupí (Vigna unguiculata L.) durante la estación seca, así como rescatar las semillas criollas producidas en el noreste de Pará. El experimento se realizó en un campo ubicado en el Instituto Federal de Educación, Ciencia y Tecnología de Pará, campus Castanhal, realizado de septiembre a noviembre de 2018. Se utilizaron cuatro variedades de caupí:

\footnotetext{
${ }^{1}$ Graduando em Agronomia, IFPA-Campus Castanhal, lucas.qifernando@outlook.com

${ }^{2}$ Graduado em Agronomia, IFPA-Campus Castanhal, breno_barbosaabada@ hotmail.com

${ }^{3}$ Graduando em Agronomia, IFPA-Campus Castanhal, gabryelgarreto@gmail.com

${ }^{4}$ Mestre em Desenvolvimento rural e gestão de empreendimentos agroalimentares, IFPA-Campus Castanhal, savio.tavares@ifpa.edu.br

${ }^{5}$ Dra. em Ciências, Docente do IFPA-Campus Castanhal, juliana.nobre@ifpa.edu.br
} 
BRS Novaera (conocido como caupí blanco), caupí rojo (conocido como mata hambre) y caupí verde (conocido como árbol de hoja perenne), todos encontrados en ciudades en la región noreste de Pará, como Marapanim, Santa Maria do Pará, Irituia y Castanhal. El experimento se realizó en bloques aleatorizados con un área de 9x5 m cada bloque, divididos en 4 parcelas de 4x2 $\mathrm{m}$, respetando el espacio de 1 metro entre parcelas dentro del bloque. Las plantas se observaron durante un período de 60 días desde la siembra, y las variables de crecimiento analizadas, el diámetro del tallo, la altura de la planta y la masa seca del brote se evaluaron cada 12 días. Después de la cosecha, se evaluaron las variables de rendimiento: número de vainas por planta, longitud de las vainas, número de semillas por vaina y peso de 100 semillas. Los datos obtenidos se sometieron a análisis de varianza y los promedios comparados por la prueba de Tukey con una probabilidad del 5\%. Para los períodos de evaluación, se realizó un análisis de regresión polinómica. Las variedades de caupí BRS Novaera, seguidas de "siempre verde" y "matar el hambre" muestran un rendimiento satisfactorio durante la estación seca, siendo una opción para que el agricultor pueda cultivar otra cosecha de frijoles durante el año. La variedad "matar el hambre" puede ser una alternativa para el abono verde y la recuperación de suelos degradados, debido a la producción expresiva de materia seca y cubierta verde en el suelo.

Palabras Clave: Vigna unguiculata L., semilla criolla, ceder.

\begin{abstract}
The study of cowpea planting time is of great importance for its production, since it is very sensitive to precipitation, temperature, irregular and poorly distributed rainfall, along with the dry season, causing enormous damage to crops. Thus, this work aimed to evaluate the performance of cowpea (Vigna unguiculata L.) varieties during the dry season, as well as to rescue the creole seeds produced in northeastern Pará. The experiment was conducted in a field located at the Federal Institute of Education, Science and Technology of Pará, Castanhal campus, conducted from September to November 2018. Four varieties of cowpea were used: BRS Novaera (known as white cowpea), red cowpea (known as kills hungry) and green cowpea (known as evergreen), all found in cities in the northeastern region of Pará, such as Marapanim, Santa Maria do Pará, Irituia and Castanhal. The experiment was conducted in randomized blocks with an area of 9x5 m each block, divided into 4 plots of $4 \times 2 \mathrm{~m}$, respecting the spacing of 1 meter between plots within the block. The plants were observed during a period of 60 days from sowing, and the growth variables analyzed, stem diameter, plant height and shoot dry mass were evaluated every 12 days. After harvest the yield variables were evaluated: number of pods per plant, length of pods, number of seeds per pod and weight of 100 seeds. The obtained data were submitted to analysis of variance and the averages compared by Tukey test at $5 \%$ probability. For the evaluation periods, a polynomial regression analysis was performed. The cowpea varieties BRS Novaera, followed by "always green" and "kill hunger" show satisfactory performance during the dry season, being an option for the farmer to be able to grow another crop of beans during the year. The "kill starvation" variety can be an alternative for green manure and recovery of degraded soils, due to the expressive production of dry matter and green cover in the soil.

Keywords: Vigna unguiculata L., Creole seed, yield.
\end{abstract}

\title{
INTRODUÇÃO
}

O feijão é uma das culturas mais cultivadas e consumidas no Brasil e no mundo, sua importância vai além do aspecto econômico, dada sua relevância ao fator de segurança alimentar, nutricional e cultural, na culinária de diversos países, sobretudo entre os extratos sociais menos favorecidos (INCAPER, 2010).

O feijão (Vigna unguiculata L.), conhecido por feijão-caupi, é originário do continente africano e foi introduzido no Brasil na segunda metade do século XVI pelos colonizadores portugueses no estado da Bahia, a partir de então, foi disseminado em todo o país, ganhando grande relevância nas regiões norte e nordeste (EMBRAPA, 2011). 
O feijão-caupi é o terceiro mais cultivado no território nacional, perdendo apenas para o feijão-rajado (Phaseolus vulgaris L.) que fica em primeiro lugar, e para o feijão-preto (Phaseolus vulgaris 'Black turtle) que ocupa o segundo lugar do ranking, sendo plantado na primeira safra 2017/2018 em uma área de 410.7 mil hectares (CONAB, 2018).

Com o aumento na produção a agricultura brasileira vem passando por um intenso processo de mudanças tecnológicas, desde o manejo das culturas até a seleção das melhores sementes, a produção de novas cultivares híbridas ou não, essas cada vez mais produtivas, precoces, resistentes a pragas, doenças e etc (FREIRE FILHO et al., 2011). Seguindo esse contexto, o feijão-caupi deixou de ser uma cultura voltada apenas para agricultores familiares e atualmente vem sendo cultivado por médios e grandes produtores, nas regiões Norte e Nordeste, devido à sua adaptação às condições edafoclimáticas. Sua importância não se restringe apenas ao território brasileiro, tendo relevância nos países da África e Ásia, principalmente, por suas características nutricionais, representando uma importante fonte de proteínas e aminoácidos essenciais que complementam a dieta do ser humano (FREIRE FILHO e ROCHA et al., 2011).

O feijoeiro é bastante sensível à deficiência hídrica, principalmente, quando essa ocorre na floração e período de enchimento dos grãos, por outro lado, possui diferentes variedades com ampla adaptação edafoclimática, o que permite o seu cultivo durante todo o ano, em quase todos os estados da federação (BURATTO et al., 2007).

Portanto, o estudo da época de plantio do feijão-caupi tem grande importância para a sua produção, visto que, ela é bastante sensível à precipitação e à temperatura do ar, chuvas irregulares e mal distribuídas, juntamente com o período de estiagem, causando danos enormes às lavouras. $\mathrm{O}$ que justifica o estudo da melhor época para o seu plantio, assim o conhecimento das variações climáticas de cada região exerce efeitos significativos sobre o desenvolvimento econômico e alimentar da região (SILVA et al., 2010).

Nesse sentido, verificar a variedade de feijão-caupi menos afetada pelo período seco, é extremamente importante, por oportunizar aos agricultores da região a possibilidade de se adquirir mais uma safra, no segundo semestre, já que o mesmo comumente é cultivado entre os meses de maio a julho. Portanto, este trabalho teve como objetivo avaliar o desempenho agronômico de diferentes variedades de feijão-caupi no período de estiagem em CastanhalPA.

\section{FUNDAMENTAÇÃO TEÓRICA}

O feijão é um alimento muito consumido pelos brasileiros, sendo um dos principais 
componentes da dieta alimentar, o mesmo possui características nutricionais que representam uma importante fonte de proteína, ferro e carboidratos na dieta humana, principalmente, em países de regiões tropicais e subtropicais (SALVADOR, 2012).

A nível nacional o feijão está entre as principais culturas cultivadas, tendo na safra 2016/2017 uma produção de 1,24 milhão de toneladas, sendo 787,6 mil toneladas de feijãocomum cores, 320 mil toneladas de feijão-comum preto e 127,9 mil toneladas de feijão-caupi, sua menor produtividade está relacionada às condições de plantio e de baixa tecnologia utilizada, sendo os principais estados produtores São Paulo e Minas Gerais (CONAB, 2018).

No estado do Pará a cultura do feijão-caupi tem grande expressão na produção

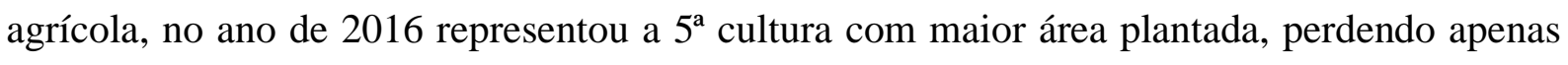
para as culturas da soja $28,71 \%$, açaí $22,70 \%$, dendê $15,66 \%$ e milho $13,29 \%$, sendo a área plantada no estado com feijão-caupi correspondendo a 13,76\% de toda área, tendo ênfase nos municípios de Capanema e Bragança. Salienta-se que os dez cultivos agrícolas de maior área plantada no Pará concentram 95\% do total destinado ao plantio no estado (FAPESPA, 2017).

Uma das grandes vantagens do feijão é sua ampla adaptação edafoclimática e suas centenas de variedades, permitindo seu cultivo durante o ano todo, em quase todos os estados brasileiros, nas diferentes épocas e safras (OLIVEIRA, 2015). Em alguns estados a seca e deficiência hídrica, causada pelos veranicos, é um dos fatores que afetam grandemente a produção agrícola do feijão-caupi, influenciando todo o processo vegetativo da cultura em questão (SILVA et al., 2016).

Os elementos climáticos são importantes para a cultura do feijão-caupi e tem a faixa ideal para o seu cultivo, pois a cultura exige uma precipitação pluvial mínima de $300 \mathrm{~mm}$ bem distribuídas, temperatura entre 18 a $34^{\circ} \mathrm{C}$, porém, algumas cultivares locais já são adaptadas ao clima de sua região (SILVA et al., 2016). Estas variedades são conhecidas como crioulas, por apresentar boa adaptação à região e por vir sendo plantado entre gerações.

São consideradas crioulas aquelas sementes que não passaram por um processo de melhoramento genético, passadas de geração a geração, e guardadas principalmente em comunidades tradicionais, como indígenas, quilombolas, ribeirinhos, caboclos e etc. (TRINDADE, 2006). Segundo Tsutsumi et al. (2012), o feijão crioulo apresenta aspecto e sabor diferenciado, possibilitando maior agregação de valor e também as variedades crioulas são mais adequadas ao cultivo orgânico, por apresentar maior resistência às doenças e pragas de sua região de origem.

As sementes crioulas fazem parte do patrimônio de diversos povos e comunidades tradicionais que ao longo dos tempos conservam, resgatam e selecionam não só sementes, 
mas também algumas raças de animais, assim conservando e mantendo sua agrobiodiversidade adaptada a cada região (NUÑEZ e MAIA, 2006).

Segundo Teixeira (2012), as sementes crioulas são de maneira geral menos produtivas do que as sementes modernas que passam por um processo de melhoramento genético e hibridação, porém, apresentam grande variabilidade genética e são resistentes a pragas, doenças e clima do seu local de origem.

Em 2003 se estabeleceu a Lei $n^{0} 10.711$ que dispõe sobre o sistema nacional de Sementes e Mudas, a mesma permitiu aos agricultores a produção, troca e venda de sementes e mudas entre si, sem precisarem aderir ao Registro Nacional de Sementes (RENASEM) e ao Registro Nacional de Cultivares (RNC), responsáveis pela fiscalização destas trocas e comercialização de sementes e mudas, essa brecha aberta na legislação foi um dos fatores que reforçaram as tentativas de legitimação das sementes crioulas por parte dos cientistas e dos agricultores ecológicos (PAULINO e GOMES, 2015).

Apesar de todos os aspectos sociais, econômicos e alimentar que permeiam às sementes crioulas e seu reconhecimento perante à legislação, muitas estão se perdendo ou deixando de ser cultivadas, sendo extremamente necessário o resgate e manutenção dessas variedades locais já adaptadas, para que o agricultor tenha autonomia, tornando-se menos dependente das sementes comerciais, melhoradas e/ou híbridas.

\section{METODOLOGIA}

O trabalho foi conduzido no período de 5 de setembro a 7 de novembro de $2018 \mathrm{em}$ campo localizado no Instituto Federal de Educação, Ciência e Tecnologia do Pará, campus Castanhal, nas coordenadas geográficas de Latitude: 1¹8'32.62'”, Longitude: 4756'51.09'”. A classificação do clima é Af de acordo com a Köppen e Geiger, apresenta temperatura média anual de $26,5^{\circ} \mathrm{C}$ e pluviosidade média de $2.432 \mathrm{~mm}$ ao ano.

A área foi previamente preparada por meio de roçagem e gradagem mecanizada. A análise de acidez potencial, macro e micronutrientes do solo foi realizada no Laboratório Terra (Goiânia-GO), cujos resultados expressaram $\mathrm{pH}=5.0, \mathrm{Ca}=2.9, \mathrm{Mg}=0.5, \mathrm{Ca}+\mathrm{Mg}=$ $3.4, \mathrm{Al}=0.00, \mathrm{H}+\mathrm{Al}=2.9, \mathrm{~K}=0.201, \mathrm{CTC}=6.40(\mathrm{Cmolc} / \mathrm{dm} 3), \mathrm{P}=14 \mathrm{Mg} / \mathrm{dm} 3($ Melich I) e M.O = $16 \mathrm{~g} / \mathrm{kg}$. Posteriormente, realizou-se a correção do solo por meio de calagem, utilizando calcário dolomítico.

A implantação ocorreu no dia 05/09/2018, período de redução das chuvas, também conhecido como verão amazônico, que vai do mês de julho a novembro. Antes da semeadura a área foi nivelada manualmente, foram semeadas sementes de 4 variedades de feijão-caupi, 
cultivadas no nordeste paraense. A aquisição dessas sementes foi por meio de doações de produtores rurais de Santa Maria do Pará, da agrovila de Bacabal (Castanhal-PA), da comunidade do Ebrom (Irituia-PA) e Boa Vista (Marapanim-PA).

Para semeadura utilizou-se o espaçamento de $20 \mathrm{~cm}$ entre plantas e $40 \mathrm{~cm}$ entre fileiras, tendo uma densidade populacional de 100 plantas por parcela. A semeadura foi feita de forma semi-mecanizada com a utilização de uma plantadeira manual, conhecida como ticotico, onde foram semeadas de 3 a 4 sementes por cova, com profundidade de 4,0 a 6,0 cm. A profundidade média de semeadura está ao redor de $4 \mathrm{~cm}$ em solos de textura argilosa e úmidos e $6 \mathrm{~cm}$ naqueles de textura arenosa, evitando-se semear muito profundamente para que não haja atraso nem estresse para a emergência da plântula, quando então, estaria mais sujeita à incidência de doenças e pragas no solo (INCAPER, 2010).

As adubações de cobertura ocorreram aos 8, 15 e 30 dias após a semeadura (DAS), a mesma foi procedida de acordo com a análise do solo, segundo as recomendações de adubação e calagem para o estado do Pará (CRAVO, 2007). Aos 12 DAS foi procedido o desbaste das plantas, deixando apenas uma em cada cova, a limpeza das parcelas se deu por meio de capina manual com o auxílio de enxadas, aos 12, 25 e 35 DAS.

O experimento foi conduzido em blocos casualizados, sendo 4 repetições $(9 \times 5 \mathrm{~m}) \mathrm{com}$ 4 parcelas de $4 \times 2 \mathrm{~m}$, na disposição nascente poente, com espaço de um metro entre cada parcela, as 4 variedades de feijão utilizadas foram: BRS Novaera (caupi branco) e variedades crioulas de feijão-caupi preto, feijão-caupi vermelho conhecido por "mata fome" e feijãocaupi verde conhecido localmente por "sempre verde".

As análises correspondentes aos componentes de crescimento iniciaram a partir dos 12 DAS, prosseguindo-se a cada 12 dias (24, 36, 48 e 60 DAS). Nas avaliações foram selecionadas 10 plantas de forma aleatória em cada parcela, respeitando o espaço de $50 \mathrm{~cm}$ das bordas, cada planta selecionada foi devidamente marcada com a utilização de um barbante de sisal, com o objetivo de analisar sempre os parâmetros das mesmas plantas durante o seu desenvolvimento. Para isso, foram avaliadas as seguintes variáveis de crescimento e rendimento:

Diâmetro do caule - utilizou-se um paquímetro analógico, tomando-se como padrão a região do colo da planta. Os resultados obtidos foram expressos em milímetros ( $\mathrm{mm}$ ).

Altura das plantas - foi realizada de acordo com a metodologia utilizada por Oliveira et al. (2015), com auxílio de fita métrica, medindo o comprimento total da planta a partir da região do colo até a inserção da folha mais alta da planta, sendo os resultados expressos em centímetros $(\mathrm{cm})$. 
Massa seca - utilizou-se a metodologia de Oliveira et al. (2015), onde foram avaliadas a parte aérea de três plantas por parcela, as plantas utilizadas para este procedimento foram colhidas manualmente aos 24 dias, repetindo a mesma análise a cada 12 dias seguintes, separando-se a parte aérea das raízes no ponto de interseção (coleto), levadas para laboratório de solos do IFPA - Campus Castanhal. No laboratório, as partes aéreas das plantas foram acondicionadas em sacos de papel kraft e levadas a estufa com circulação de ar a $65{ }^{\circ} \mathrm{C}$, durante 72 horas, em seguida, pesadas em balança de precisão, sendo os resultados expressos em gramas $(g)$.

Número de vagens por planta - foi contabilizado a partir dos 36 DAS, período em que as plantas estavam em floração e algumas já apresentavam as primeiras vagens, e então foram contabilizadas a cada 12 dias, estendendo-se até os 60 dias.

Comprimento das vagens - foram medidas 20 vagens, escolhidas aleatoriamente de cada parcela, com auxílio de régua flexível milimetrada, sendo os resultados expressos em centímetros

Número de sementes por vagem - foi contabilizado de 20 vagens aleatórias de cada parcela, as mesmas foram debulhadas e suas sementes contadas manualmente.

Peso de 100 sementes - utilizou-se 100 sementes colhidas em cada parcela, posteriormente, foram pesadas em balança de precisão, sendo os resultados expressos em gramas ( $\mathrm{g}$ ).

\section{RESULTADOS E DISCUSSÃO}

Os dados climáticos de temperatura $\left({ }^{0} \mathrm{C}\right)$ e precipitação $(\mathrm{mm})$ ocorridos em CastanhalPA em 2018, encontram-se no quadro 01. Verifica-se que no período em que o experimento foi realizado (setembro a novembro), ocorreram as menores médias de precipitação, variando de 63 a $81 \mathrm{~mm}$. Demonstrando que de fato este é um período de redução significativa das chuvas, quando comparado ao mês de março/2018 onde houve a maior concentração da precipitação $(411 \mathrm{~mm})$. Neste caso, a soma da precipitação dos 3 meses em que o trabalho foi realizado $(223 \mathrm{~mm})$, corresponde a $54 \%$ das chuvas concentradas em março.

Quadro 01: Dados meteorológicos ocorridos em Castanhal-PA, 2018.

\begin{tabular}{|c|c|c|c|c|c|c|c|c|c|c|c|c|}
\hline & JAN & FEV & MAR & ABR & MAI & JUN & JUL & AGO & SET & OUT & $\mathrm{NOV}$ & DEZ \\
\hline $\begin{array}{l}\text { Temp. } \\
\text { máx. }\end{array}$ & 30.4 & 29.9 & 29.5 & 30.7 & 31.1 & 31.1 & 31.4 & 31.6 & 32.9 & 32.3 & 32 & 31.6 \\
\hline $\begin{array}{l}\text { Temp. } \\
\text { mín. }\end{array}$ & 22.1 & 22.3 & 22.1 & 22,5 & 21.9 & 21.6 & 21.6 & 21.7 & 21.7 & 21.8 & 21.9 & 22 \\
\hline
\end{tabular}




\begin{tabular}{l|llllllllllll} 
Temp. & 26.2 & 26.1 & 25.8 & 26.6 & 26.6 & 26.3 & 26.5 & 26.6 & 26.8 & 27 & 26.9 & 26.8 \\
méd. & & & & & & & & & & & & \\
Chuvas & 307 & 336 & 411 & 355 & 242 & 155 & 125 & 115 & 81 & 79 & 63 & 152 \\
$(\mathbf{m m})$ & & & & & & & & & & & & \\
\hline
\end{tabular}

Fonte: Climate-Data.Org.

O resultado da análise de variância referente às variáveis de crescimento das variedades de feijão-caupi, analisadas em diferentes períodos, encontram-se na tabela 1. Verifica-se que houve interação significativa (variedades*período) apenas para a altura de plantas, no entanto, para o diâmetro de plantas, houve efeito isolado dos fatores, já para a massa seca apenas o fator período foi significativo.

Tabela 1. Resumo da análise de variância referente as variedade de feijão-caupi produzidas no período de estiagem. Castanhal-PA, 2018.

\begin{tabular}{|c|c|c|c|c|c|}
\hline \multirow[t]{2}{*}{ Fonte de variação } & \multirow[b]{2}{*}{ GL } & \multicolumn{4}{|c|}{ Quadrados médios } \\
\hline & & $\begin{array}{l}\text { Diâmetro } \\
(\mathrm{mm})\end{array}$ & $\begin{array}{c}\text { Altura } \\
(\mathrm{cm})\end{array}$ & GL & $\begin{array}{c}\text { Massa seca } \\
(\mathrm{g})\end{array}$ \\
\hline Variedade & 3 & $1.853^{*}$ & $356.703 * *$ & 3 & $6.335^{\mathrm{NS}}$ \\
\hline Período & 4 & $33.105 * *$ & $2806.682 * *$ & 3 & $33.913 *$ \\
\hline Variedade*Período & 12 & $0.241^{\mathrm{NS}}$ & $34.076^{* *}$ & 9 & $12.334^{\mathrm{NS}}$ \\
\hline Bloco & 3 & $2.216 * *$ & $20.568^{\mathrm{NS}}$ & 3 & $2.019^{\mathrm{NS}}$ \\
\hline Resíduo & 57 & 0.399 & 9.254 & 45 & 10.874 \\
\hline Total & 79 & & & 63 & \\
\hline $\begin{array}{c}\text { C.V }(\%) \\
\text { Média geral }\end{array}$ & 4.37 & 14.45 & $31.45^{9.67}$ & 4.61 & 71.42 \\
\hline
\end{tabular}

Significativo a $1 \%(* *)$ e $5 \%(*)$ de probabilidade; não significativo $\left({ }^{\mathrm{NS}}\right)$.

Com relação ao diâmetro do caule avaliado durante os diferentes períodos, observa-se um comportamento, com todas as variedades, se ajustando ao modelo quadrático da regressão. No entanto, a variedade "mata fome" obteve o maior diâmetro $(6,25 \mathrm{~mm})$ e o "sempre verde" o menor (5,22 mm) aos 60 DAS (Figura 1).

Um dos motivos para a diferença no diâmetro das plantas avaliadas, pode estar relacionado a eficiência do sistema radicular em absorver água e nutrientes do solo, mesmo em períodos de estiagem, pois todas as variedades receberam o mesmo tratamento no que diz respeito à adubação. 
Figura 2: Diâmetro do caule de plantas de feijão-caupi de diferentes variedades, avaliada no período de estiagem em Castanhal-PA, 2018.

\section{Caupi preto}

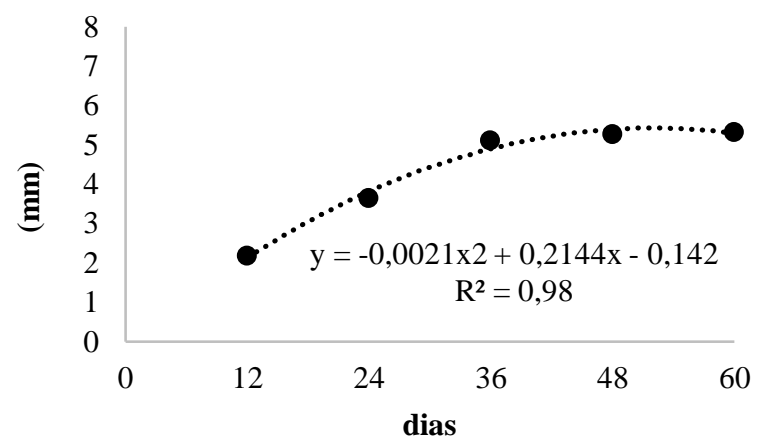

Mata fome

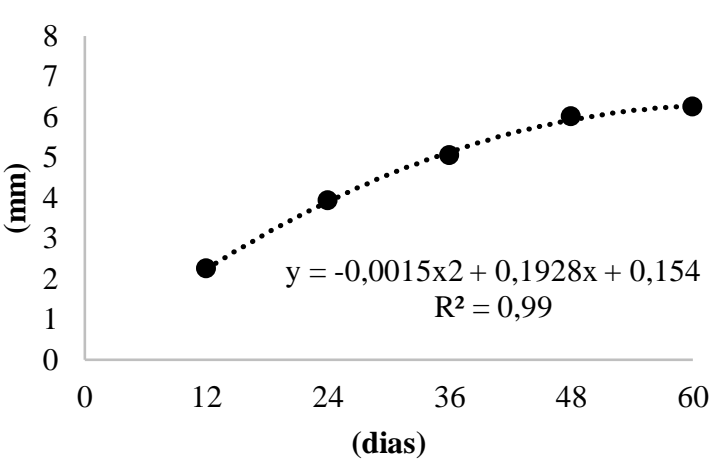

BRS Novaera

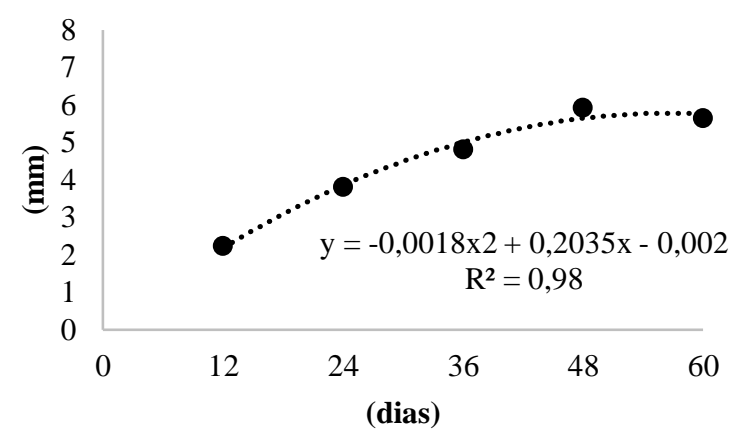

Sempre verde

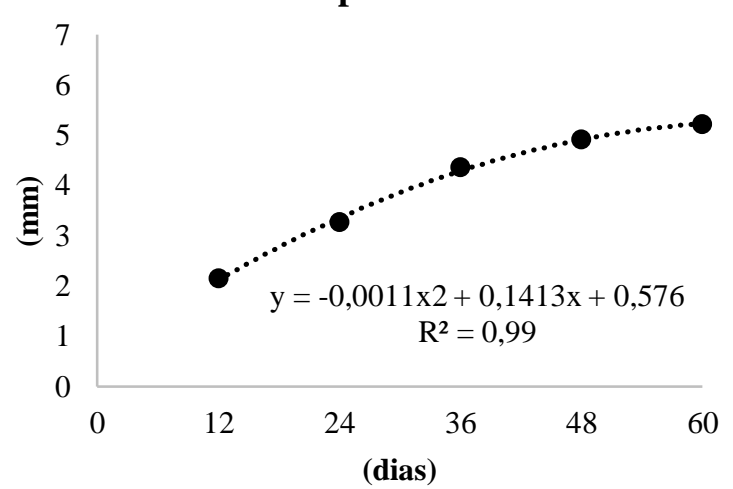

Em relação à altura das plantas (Figura 2), observa-se que as variedades que mais se destacaram no crescimento foram "mata fome" $(53,22 \mathrm{~cm})$, seguido da variedade "BRS Novaera" $(49,02 \mathrm{~cm})$, já as menores plantas foram verificadas na variedade "caupi preto" $(38,05 \mathrm{~cm})$.

Figura 3. Altura de plantas de feijão-caupi, avaliadas no período de estiagem em Castanhal-PA, 2018.

\section{Caupi preto}

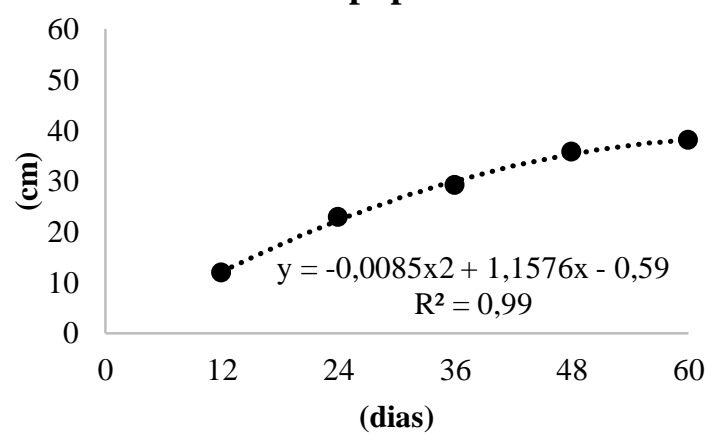

BRS Novaera

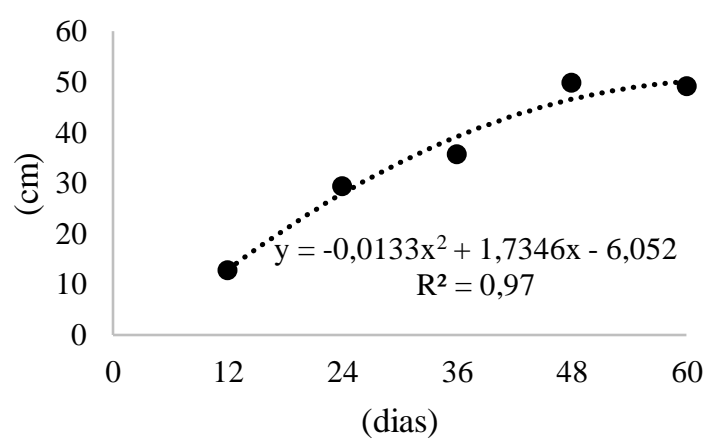



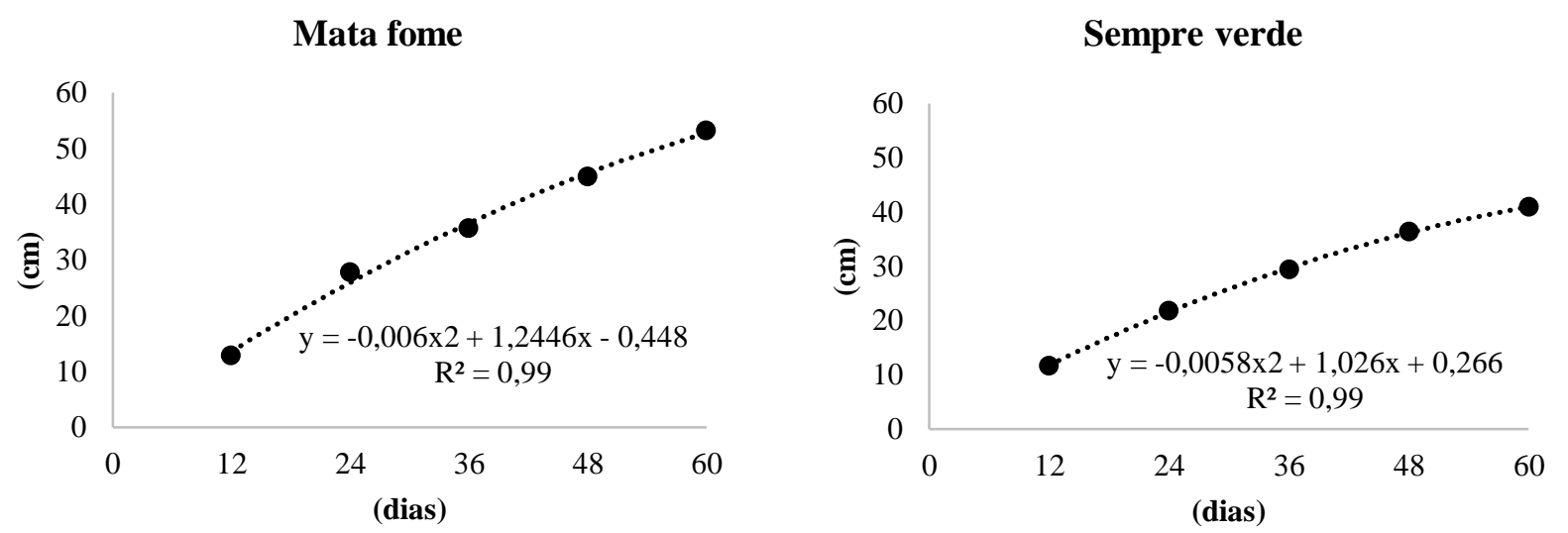

O maior peso de massa seca observado aos 60 DAS foi da variedade "Novaera" $(7,06$ g), seguida das variedades crioulas caupi preto $(6,28 \mathrm{~g})$, sempre verde $(4,79 \mathrm{~g})$ e mata fome $(3,46 \mathrm{~g})$. Vale ressaltar que para as variedades "mata fome" e "sempre verde" não houve ajuste a nenhum modelo de regressão (Figura 3).

Com os resultados de massa seca, também verifica-se que as duas variedades com maior massa podem ser boas opções de adubação verde, podendo depositar quantidade de matéria orgânica, considerando uma população de 250.000 plantas/ha ${ }^{-1}$ a variedade "Novaera" poderia depositar uma quantidade igual a $1.765 \mathrm{~kg} / \mathrm{ha}$ e a variedade caupi preto depositaria $1.570 \mathrm{~kg} / \mathrm{ha}^{-1}$, podemos chegar a esse valor multiplicando o número populacional de plantas pelo peso médio da matéria seca (Novaera 7,06 g e caupi preto 6,28 g).

Figura 4. Massa seca da parte aérea de plantas de feijão-caupi , avaliada no período de estiagem em CastanhalPA, 2018.

\section{Caupi preto}

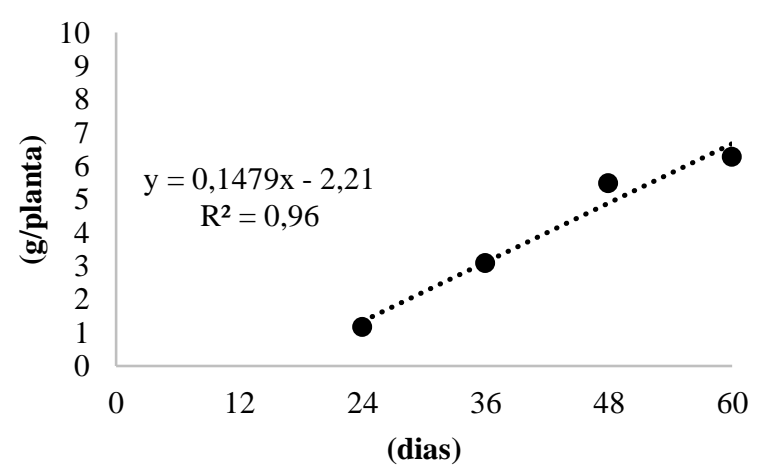

BRS Novaera

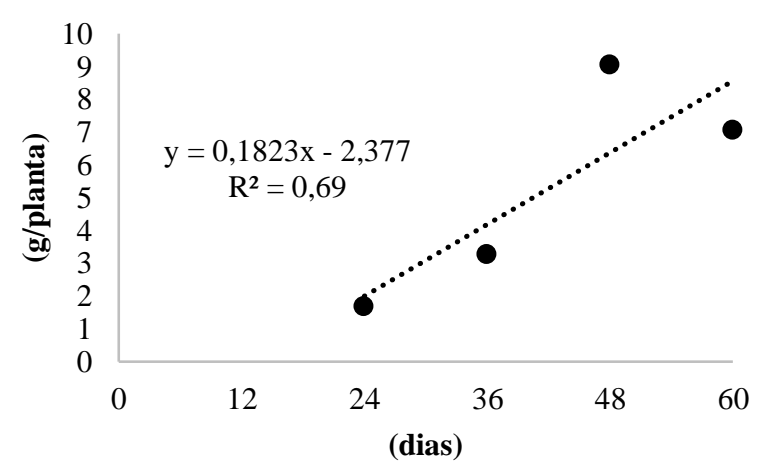


Mata fome

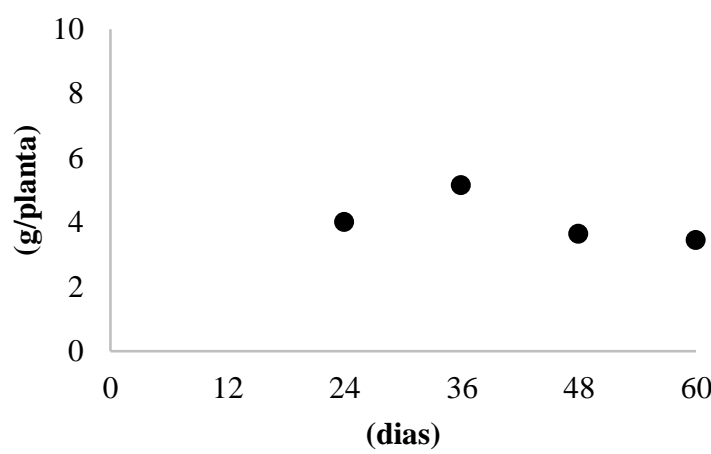

Sempre verde

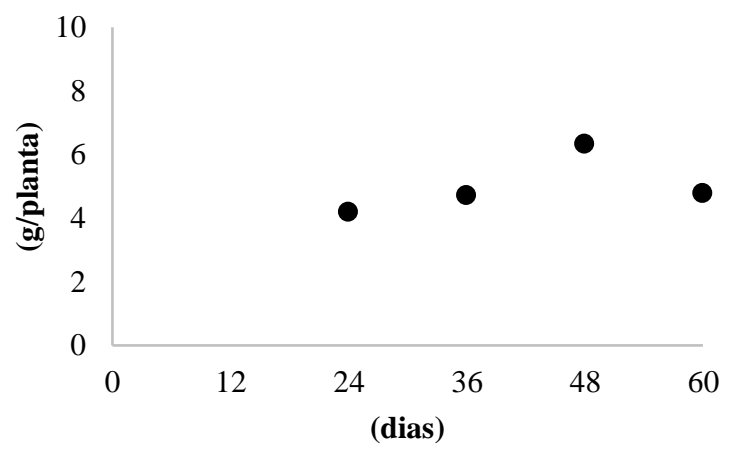

Fazendo uma abordagem geral das cultivares (Tabela 2), observa-se que para diâmetro do caule, a variedade "mata fome" apresentou a maior média, não diferindo das variedades "Novaera e caupi preto". Com relação à altura de plantas "Novaera e mata fome" foram superiores, no entanto, na massa seca todas foram iguais estatisticamente.

O maior crescimento vegetativo das variedades "mata fome" e "Novaera" podem estar associados a uma maior adaptação às condições de baixa disponibilidade hídrica, durante o cultivo.

Tabela 2. Médias referentes ao diâmetro $(\mathrm{mm})$, altura de plantas $(\mathrm{cm})$ e massa seca da parte aérea $(\mathrm{g})$ de variedades de feijão-caupi, cultivadas no período de estiagem. Castanhal-PA, 2018.

\begin{tabular}{c|ccc}
\hline Cultivar & Diâmetro & Altura & Massa seca \\
\hline Caupi preto & $4,31 \mathrm{ab}$ & $27,56 \mathrm{~b}$ & $4,08 \mathrm{a}$ \\
Novaera & $4,49 \mathrm{ab}$ & $35,29 \mathrm{a}$ & $5,28 \mathrm{a}$ \\
Mata fome & $4,70 \mathrm{a}$ & $34,91 \mathrm{a}$ & $4,06 \mathrm{a}$ \\
Sempre verde & $3,98 \mathrm{~b}$ & $28,03 \mathrm{~b}$ & $5,01 \mathrm{a}$ \\
\hline
\end{tabular}

Médias seguidas de mesma letra na coluna, não diferem entre si pelo teste de Tukey a 5\% de probabilidade.

Na tabela 3 encontram-se os resultados da análise de variância referente aos componentes de rendimento das variedades de feijão-caupi, produzidas no período de estiagem. Verifica-se que apenas o número de sementes por vagem não foi significativo, já o número de vagens por planta e peso de 100 sementes apresentaram diferença significativa com relação às variedades.

Tabela 3. Análise de variância dos componentes de rendimento das variedades de feijão-caupi, cultivadas no período de estiagem. Castanhal-PA, 2018.

\begin{tabular}{cccccc}
\hline $\begin{array}{c}\text { Fonte de } \\
\text { variação }\end{array}$ & GL & $\begin{array}{c}\text { Quadrados médios } \\
\text { Comprimento } \\
\text { de vagem } \\
(\mathrm{cm})\end{array}$ & $\begin{array}{c}\text { Número de } \\
\text { sementes } \\
\text { por vagem }\end{array}$ & $\begin{array}{c}\text { Número de } \\
\text { vagens por } \\
\text { planta }\end{array}$ & $\begin{array}{c}\text { Peso de } \\
100 \\
\text { sementes }\end{array}$ \\
\hline Cultivar & 3 & $7,310^{*}$ & $9,413^{\mathrm{NS}}$ & $12,688^{*}$ & $4,445^{* *}$ \\
Bloco & 3 & $0,843^{\mathrm{NS}}$ & $1,622^{\mathrm{NS}}$ & $0,793^{\mathrm{NS}}$ & $0,385^{\mathrm{NS}}$ \\
Resíduo & 9 & 2,654 & 3,327 & 1,167 & 0,111 \\
Total & 15 & & & & \\
CV $(\%)$ & & 9,62 & 19,29 & 38,16 & 1,81 \\
\hline
\end{tabular}




\begin{tabular}{|c|c|c|c|c|}
\hline Média geral & 16,93 & 9,50 & 2,83 & 18.42 \\
\hline
\end{tabular}

O comprimento de vagem foi maior para a variedade "mata fome" $18,86 \mathrm{~cm}$, no entanto, não diferiu estatisticamente das variedades "Novaera" e "sempre verde". Apesar de não ter apresentado diferença significativa, o número de sementes foi maior para a variedade "mata fome" com 12 sementes por vagem, porém, sua média de vagem por planta foi apenas 1 (uma), tornando-a pouco produtiva em relação as outras variedades. A variedade "Novaera" obteve o maior número de vagens por planta, se destacando e diferindo estatisticamente das demais.

As sementes mais pesadas foram produzidas pela variedade Novaera $(19,25 \mathrm{~g})$, não diferindo estatisticamente das variedades sempre verde e mata fome (18,86 e 18,68 g, respectivamente). No entanto, o "caupi preto" foi o mais afetado pelas condições de estiagem, não conseguindo na fase de enchimento das sementes, estocar de forma mais eficiente os nutrientes nos seus tecidos de reserva (cotilédones).

Vale ressaltar também que a variável peso de 100 sementes pode ser correlacionada ao vigor das mesmas, pois àquelas mais pesadas, teoricamente, teriam mais reservas e energia para início e manutenção da germinação, assim como, o desenvolvimento inicial das plântulas.

Tabela 4. Médias referentes aos componentes de rendimento das cultivares de feijão-caupi, cultivadas no período

\begin{tabular}{ccccc} 
Comprimento de & $\begin{array}{c}\text { Número de } \\
\text { sementes } \\
\text { vagem }(\mathrm{cm})\end{array}$ & $\begin{array}{c}\text { Número de } \\
\text { vagens por } \\
\text { planta }\end{array}$ & $\begin{array}{c}\text { Peso de } 100 \\
\text { sementes }(\mathrm{g})\end{array}$ \\
\hline Caupi preto & $15,71 \mathrm{~b}$ & $9,75 \mathrm{a}$ & $2,50 \mathrm{~b}$ & $16,88 \mathrm{~b}$ \\
Novaera & $16,69 \mathrm{ab}$ & $8,75 \mathrm{a}$ & $5,25 \mathrm{a}$ & $19,25 \mathrm{a}$ \\
Mata fome & $18,86 \mathrm{a}$ & $11,50 \mathrm{a}$ & $1,00 \mathrm{~b}$ & $18,68 \mathrm{a}$ \\
Sempre verde & $16,48 \mathrm{ab}$ & $8,00 \mathrm{a}$ & $3,00 \mathrm{~b}$ & $18,86 \mathrm{a}$ \\
\hline
\end{tabular}

Letras minúsculas seguidas na coluna não diferem estatisticamente pelo teste de Tukey a 5\% de probabilidade.

De acordo com a densidade populacional indicada por Sousa (2017), para a produção de feijão-caupi que é de 160 a 340 mil plantas há-1, se a variedade "Novaera" obtiver o mesmo desempenho alcançado no experimento, podemos utilizar a fórmula: $\left(\left(\mathrm{N}^{\circ} \mathrm{de}\right.\right.$ sementes/vagem $\times \mathrm{N}^{\circ}$ vagens/planta $\times \mathrm{N}^{\circ}$ populacional $\left.) \div(100)\right) \times($ peso de 100 sementes $\div$ 1000), ter uma estimativa de produção entre 1.415 a $3.006 \mathrm{~kg} / \mathrm{ha}^{-1}$, o que renderia uma faixa de 23 a 50 sacas de $60 \mathrm{~kg}$ por hectare, já a segunda variedade mais produtiva o "caupi preto" se fosse plantada na mesma densidade populacional teria uma produtividade estimada em 810 a $1.720 \mathrm{~kg} / \mathrm{ha}^{-1}$, o que renderia de 13 a 28 sacas por hectare. 


\section{CONCLUSÕES}

As variedades de feijão-caupi BRS Novaera, seguida da "sempre verde" e "mata fome" apresentam desempenho satisfatório no período de estiagem, sendo uma opção para o agricultor poder cultivar mais uma safra de feijão durante o ano.

A variedade "mata fome" pode ser uma alternativa para adubação verde e recuperação de solos degradados, devido a produção expressiva de matéria seca e cobertura verde no solo.

\section{REFERÊNCIAS}

BOLETIM AGROPECUÁRIO DO PARÁ 2017. Fundação Amazônia de Amparo a Estudos e Pesquisas do Pará http://www.fapespa.pa.gov.br/upload/Arquivo/anexo/1383.pdf?id=1533567716. Acessado em: 20/02/2019.

BURATTO, J. S.; MODA-CIRINO, V.; FONSECA JÚNIOR, N. S.; PRETE, C. E. C.; FARIA, R. T. de. Adaptabilidade e estabilidade produtiva em genótipos precoces de feijão do estado do Paraná. Semina: Ciências Agrárias, Londrina, v. 28, n. 3, p. 373- 380, jul./set. 2007.

CLIMATE-DATA.ORG. Pesquisado em: https://pt.climate-data.org/america-dosul/brasil/para/castanhal-26632/\#climate-graph. Acessado em: 17/03/2018.

CONAB; Observatório agrícola, acompanhamento da safra brasileira de grãos. V.5 safra 2017/2018 - N. 7 - Sétimo levantamento, Brasília. p. 66 / Abril 2018.

CONAB - COMPANIA NACIONAL DE ABASTECIMENTO; OBSERVATÓRIO AGRÍCOLA. ACOMPANHAMENTO DA SAFRA BRASILEIRA DE GRÃOS, ISSN: 23186852. V. 5 - SAFRA 2017/18- N. 4 - Quarto levantamento |JANEIRO 2018.

Fundação Amazônia de Amparo a Estudos e Pesquisas do Pará - Fapespa. Boletim agropecuário do Pará, 2017.

FILHO, F. R. F; et., al. Feijão-Caupi no Brasil Produção, melhoramento genético, avanços e desafios. Embrapa Meio-Norte. Teresina, PI, 2011.

FILHO, F. R. F. RIBEIRO, V. Q.; ROCHA, M. M.; SILVA, K. J. D.; NOGUEIRA, M. S. R.; RODRIGUES, E. V. Produção, melhoramento genético e potencialidades do feijão-caupi no Brasil. IV Reunião de Biofortificação. Teresina-PI, Brasil, 2011.

INCAPER. Informações técnicas para o cultivo do feijoeiro-comum na região centralbrasileira: 2009/2010. Vitória, ES, 2010.

NUÑEZ, P. B. P.; MAIA. A. L. Sementes crioulas: um banco de biodiversidade. Revista Brasileira de Agroecologia, v. 1, n. 2, 2006.4p. 
OLIVEIRA, L. F. R. Avaliação de genótipos de feijoeiro comum, do grupo carioca, na época de inverno, em Uberlândia-MG. Uberlândia - MG Junho/2015

Oliveira, L. F. F. A. et., al. Crescimento e produtividade de duas cultivares de feijão em função de doses de ácido 2,3,5-triiodobenzoico. Ciência Rural, Santa Maria, v.45, n.12, p.2181-2186, 2015.

PAULINO, J. S.; GOMES, R. A. Sementes da Paixão: agroecologia e resgate da tradição. Revista de Economia e Sociologia Rural, v. 53, n. 3, p.517-528, 2015.

SALVADOR, C. A.; SEAB - Secretaria de Estado da Agricultura e do Abastecimento DERAL - Departamento de Economia Rural. Feijão - Análise da Conjuntura Agropecuária. 2012.

SILVA, C. M. et. al. Época de semeadura no desempenho agronômico do feijão-caupi. I CONGRESSO INTERNACIONAL DA DIVERSIDADE DO SEMIÁRIDO. Universidade Federal do Piauí - UFPI, 2016.

SILVA, P. I. B. e; NEGREIROS, M. Z. de; MOURA, K. K. C. de F.; FREITAS, F. C. L. de; NUNES, G. H. de S.; SILVA, P. S. L. e; GRANGEIRO, L. C.; Crescimento de pimentão em diferentes arranjos espaciais. Pesquisa Agropecuária Brasileira, Brasília, v. 45, n. 2, 2010. p. 132-139.

SOUSA, R. R.; DENSIDADE POPULACIONAL E INOCULAÇÃO NA CULTIVAR DE FEIJÃO-CAUPI BRS IMPONENTE; Dissertação (Mestrado em Agronomia) - Universidade Federal do Piauí, Teresina, 2017.

TEIXEIRA, W.V., MALTA, C.G., LEANDRO, W.M. Produtividade e avaliação da capacidade de expansão de milho pipoca crioulo em cultivo isolado e consorciado com feijãode-porco. Enciclopédia Biosfera, Centro Científico Conhecer - Goiânia, v.8, N.14; p. 7782012.

TRINDADE, C.C. Sementes crioulas e transgênicos, uma reflexão sobre sua relação com as comunidades tradicionais. XV Congresso Nacional do Conpedi, Manaus, Amazonas. 2006.

TSUTSUMI, Cláudio Y. et al. Cultivares de feijão produzidos em sistema de cultivo orgânico. Cultivando o Saber. v. 5, n. 3, p. 123 - 131. Cascavel, 2012. 